\title{
Diferentes condimentos vegetais: avaliação sensorial e de atividade antibacteriana em preparação alimentar com frango cozido
}

\author{
RODRIGUES, F.'; CARVALHO, H.H.C. ${ }^{2}$; WIEST, J.M..12*
}

1 Programa de Pós-Graduação em Ciências Veterinárias da Universidade Federal do Rio Grande do Sul, Avenida Bento Gonçalves, 9090, CEP 91501-970, Porto Alegre-Brasil Instituto de Ciência e Tecnologia de Alimentos da Universidade Federal do Rio Grande do Sul, Avenida Bento Gonçalves, 9.500, Caixa Postal 15090, CEP: 91501 970, Porto Alegre-Brasil *00002497@ufrgs.br

\begin{abstract}
RESUMO: A partir da atividade antibacteriana in vitro, predeterminada em doze plantas com indicativo etnográfico condimentar, testou-se este atributo in loco no modelo caldo com frango cozido. Primeiramente, procedeu-se ao treinamento de 10 avaliadores, segundo a legislação vigente quanto ao Consentimento Livre e Esclarecido, oportunizando conhecimentos prévios sobre as plantas salsa (Petroselinum sativum), manjerona branca (Origanum X aplii), manjerona preta (Origanum majorana), manjericão (Ocimum basilicum), sálvia (Salvia officinalis), tomilho (Thymus vulgaris), anis verde (Ocimum sellol), alfavaca (Ocimum gratissimum), alho nirá (Allium tuberosum), alho poró (Allium porrum), cúrcuma (Curcuma longa) e pimenta dedo-de-moça (Capsicum baccatum). Realizou-se, através da adição individualizada desses condimentos ao caldo com frango cozido, um Teste de Aceitação tipo escala hedônica, selecionando, dentre os doze condimentos, quatro deles que se destacaram sensorialmente, a pimenta dedo-de-moça, o alho nirá, o alho poró e o tomilho. Foi feito, então, um Teste de Aceitação de concentrações denominadas pequena, média e grande destes quatro condimentos, para determinação da intensidade sensorialmente melhor aceita. As quantidades eleitas $(0,5 \mathrm{~g}$ de pimenta dedo-demoça, $15 \mathrm{~g}$ de alho nirá, $15 \mathrm{~g}$ de alho poró e $5 \mathrm{~g}$ de tomilho) foram acrescidas ao caldo com frango cozido, sendo estes desafiados frente a Escherichia coli (ATCC 11229) em concentração final de 10 UFC mL-1, limite tolerado pela legislação, tendo como grupo-controle o caldo com frango cozido sem condimentos. O crescimento bacteriano foi aferido a cada duas horas após a inoculação, até completar 24 horas de confronto, utilizando-se meio seletivo para coliformes termo-resistentes e incubação constante a $25^{\circ} \mathrm{C}$ em DBO, sendo atribuídos valores arbitrários às variações logarítmicas de crescimento. Comparados ao controle, todos os tratamentos condimentados apresentaram, individualmente, atividade antibacteriana significativa, mesmo que sem significância quando comparados entre si. Contudo, em relação ao tempo de início da atividade antibacteriana, destacou-se a pimenta dedo-de-moça, enquanto que, em relação ao prolongamento dessa ação no tempo, destacou-se o alho nirá. As 12 plantas condimentares em estudo tiveram atestada a sensorialidade, sendo que as quatro plantas com destaque tiveram a atividade anti-coliforme termo-resistente comprovada in loco. Diferentes condimentos vegetais foram capazes de fornecer qualificação sensorial e sanitária em caldo com frango cozido, em condições domésticas de manuseio.
\end{abstract}

Palavras-chave: frango condimentado, análise sensorial, análise antibacteriana, coliformes fecais

ABSTRACT: Different spice plants: sensorial evaluation and antibacterial activity in chicken broth. Based on the in vitro antibacterial activity predetermined for 12 spice plants with ethnographic indicator, this feature was tested in loco in the model cooked chicken broth. First, ten evaluators were trained, according to the current legislation for Free and Informed Consent, providing previous knowledge about the plants parsley (Petroselinum sativum), marjoram (Origanum $\mathrm{X}$ aplii and Origanum majorana), basil (Ocimum basilicum), common sage (Salvia officinalis), thyme (Thymus vulgaris), anis-like spice (Ocimum sellol), african basilicum (Ocimum gratissimum), nirá garlic (Allium tuberosum), leek (Allium porrum), turmeric (Curcuma longa) and "dedo-de-moça" chili (Capsicum baccatum). Those spices were individually added to the chicken broth to perform a

Recebido para publicação em 22/03/2010

Aceito para publicação em 07/01/2011

Rev. Bras. PI. Med., Botucatu, v.13, n.3, p.342-348, 2011. 
Hedonic Scale-like Acceptance Test, selecting four of the twelve spices that had higher sensory acceptance, "dedo-de-moça" chili, nirá garlic, leek and thyme. A new Acceptance Test was then performed using low, medium and high concentrations of those four spices to establish the most acceptable sensory intensities. The elected quantities $(0.5 \mathrm{~g}$ "dedo-de-moça" chili, $15 \mathrm{~g}$ nirá garlic, $15 \mathrm{~g}$ leek and $5 \mathrm{~g}$ thyme) were added to the chicken broth, then challenged with Escherichia coli (ATCC 11229) at a final 10 concentration of CFU $/ \mathrm{mL}$, the tolerated limit according to legislation. The control group was chicken broth without spices. The bacterial growth was measured at every two hours after the inoculation until 24 hours of confront were completed, using a selective medium for thermo-resistant coliforms, under constant incubation at $25^{\circ} \mathrm{C}$ in $\mathrm{DBO}$. Arbitrary values were assigned to the logarithmic growth variations. Compared to the control group, all the spiced treatments individually presented significant antibacterial activity, although the latter was not significant when treatments were compared with each other. However, as regards the antibacterial activity starting time, "dedo-de-moça" chili had the best results, whereas nirá garlic had the best results as regard the extension of this activity time. The 12 studied spice plants had their sensorial characteristics attested, and the four plants that had the best results had proved in loco antithermo-resistant coliform activity. Different spice plants were capable of providing sensory and sanitary qualification in chicken broth, under domestic conditions of manipulation.

Key words: spicy chicken, sensory evaluation, antibacterial analysis, fecal coliforms

\section{INTRODUÇÃO}

Nas últimas décadas, verifica-se aumento expressivo no uso de plantas condimentares em decorrência de alguns fatores como, por exemplo, a valorização do uso de produtos mais naturais e também o fato de que as pesquisas, nas áreas farmacológicas e médicas, confirmam a eficácia de muitas das plantas condimentares (Furlan, 2007). Ressalta-se ainda que a qualidade de uma planta condimentar esteja quase sempre relacionada com a presença de grupo de substâncias chamadas de óleo essencial, havendo, porém, exceções, como acontecem com as pimentas do gênero Capsicum, que tem como principal responsável a capsaicina e que é classificada como alcalóide.

Do ponto de vista alimentar, à parte o valor energético intrínseco do condimento, geralmente modesto, ele é sempre complementação e integração da alimentação, para que ela seja mais agradável ao olfato, ao paladar e à vista, estimulando o apetite e a digestão. A função alimentar dos aromas é sumamente importante, pelo gosto que eles conferem aos alimentos, pela digestão dos mesmos, a começar pela salivação, além do fato de muitas plantas aromáticas usadas na cozinha terem valor alimentar intrínseco (Maranca, 1985).

A carne de frango está cada vez mais presente na alimentação da população brasileira, devido à maior busca por dietas com carne branca e menor preço em relação à carne bovina fato demonstrado pela evolução do consumo interno do país (Notícias De Mercado, 2009). O Brasil atingiu, no ano passado, consumo de carne de frango da ordem de 38,5 quilos por habitante. Esse é o quarto maior volume de consumo per capita, ficando atrás somente dos Estados Unidos, com 45,1 quilos, da Venezuela, com 39,4 quilos, e da Malásia, com 38,7 quilos (Safras \& Mercado, 2009). A carne de frango é comumente utilizada em preparos alimentares diversos, incluindo canjas, sopas e caldos.

Germano \& Germano (2003) esclarecem que qualquer alimento exposto à contaminação fecal, seja através da água de preparo ou dos manipuladores infectados, é capaz de veicular a E. coli. Nas mesmas condições, a carne de aves, em especial de galinha, tem sido apontada como causa de surtos de toxinfecção alimentar, principalmente a enteropatogênica.

Carvalho et al. (2005), estudando antimicrobianos naturais, avaliaram in vitro a atividade antibacteriana de 21 plantas com indicativo etnográfico condimentar, sendo encontrada atividade significativa em 12 delas. Os autores afirmam que os condimentos e ervas podem ter mais que uma função em alimentos aos quais são acrescidos. Em adição à propriedade sensorial, certos condimentos podem prolongar a vida útil de estocagem de alimentos pela atividade bacteriostática e/ou bactericida, prevenindo o início da deterioração e, inclusive, o crescimento de microrganismos indesejáveis.

O presente trabalho teve como objetivo avaliar a potencialidade sensorial de 12 condimentos vegetais com comprovada atividade antibacteriana in vitroem caldo com frango cozido, preparação corrente na alimentação humana. Objetivou, ainda, habilitar um grupo de testadores quanto à apreciação sensorial de 12 espécies condimentares. E, por fim, descrever a atividade anti-Escherichia coli de condimentos que se destacaram sensorialmente, in loco (caldo com frango cozido), segundo padrões sanitários de 
contaminação toleráveis em pratos à base de carnes, estabelecidos na legislação nacional.

\section{MATERIAL E MÉTODO}

O experimento foi realizado em três etapas. Na primeira e na segunda etapas, procedeu-se ao treinamento de um grupo de avaliadores para a realização das análises sensoriais, visando selecionar os condimentos vegetais sensorialmente mais adequados ao caldo com frango cozido, dentre os 12 condimentos vegetais comprovadamente antibacterianos testados in vitro por Carvalho et al. (2005). Na terceira etapa, foram conduzidos os testes de desafio bacteriológico. Após submissão e aprovação do experimento pelo Conselho de Ética da Universidade Federal do Rio Grande do Sul UFRGS (Processo UFRGS 23078.022540/09-85) procedeu-se ao treinamento de 10 provadores voluntários participantes, docentes, acadêmicos e funcionários do Instituto de Ciência e Tecnologia de Alimentos-UFRGS, conforme a Resolução ANVISA oo 196/96 (Brasil, 1996), formalizando-se o Consentimento Livre e Esclarecido. As plantas condimentares foram apresentadas, devidamente identificadas, para que os avaliadores se familiarizassem com a aparência, aroma e sabor, sendo, assim, capacitados para verbalizar as sensações, trabalhar em grupo e demonstrar reprodutibilidade nas análises sensoriais consecutivas. As amostras de plantas condimentares foram colhidas no outono de 2009, provenientes de cultivos agroecológicos da região metropolitana de Porto Alegre-RS (região climática da Depressão Central do Estado, com coordenadas de 300's e $51^{\circ} 40^{\prime} \mathrm{W}$, com altitude aproximada de $40 \mathrm{~m}$ ). Foram utilizadas folhas e caules, bem como frutos sem sementes (pimenta dedo-de-moça). As amostras de plantas usadas neste trabalho foram provenientes da mesma origem das plantas caracterizadas e identificadas botanicamente por Marodin (2004) no trabalho de Carvalho et al. (2005) partindo de exsicatas segundo Ming (1996), registradas e depositadas junto ao Herbário do Instituto de Biociências/Departamento de Botânica da UFRGS, Porto Alegre/RS, Brasil, registradas entre os números 128.937 e $130.208 . \mathrm{Na}$ caracterização inicial destas plantas, a saber: alfavaca (Ocimum gratissimum L. - Labiatae), alho nirá (Allium tuberosum Rottler ex Sprengl - Liliaceae), alho poró (Allium porrum L. - Liliaceae), anis verde (Ocimum selloiBenth. - Labiatae), cúrcuma (Curcuma longa L. - Zingiberaceae), manjericão (Ocimum basilicum L. - Labiatae), manjerona branca (Origanum $X$ aplii (Domin) Boros - Lamiaceae), manjerona preta (Origanum majorana, L. - Lamiaceae), pimenta dedode-moça (Capsicum baccatum L. var. pendulum Solanaceae), salsa (Petroselinum sativum Hoffm. -
Apiaceae), sálvia (Salvia officinalis L. - Lamiaceae) e tomilho (Thymus vulgaris L. - Lamiaceae), seguiramse indicativos de Bremness (1993), Backes \& Nardino (2001) e Lorenzi \& Matos (2002).

A partir do modelo alimentar escolhido para o estudo, definiu-se a composição do caldo com frango cozido com base na receita do Centro Médico da Universidade de Nebraska/EUA - University of Nebraska Medical Center (Rennard et al., 2000). Foram feitos preparos de frango na proporção de 1:10, contendo $300 \mathrm{~g}$ de carne de coxas e sobrecoxas de frango industrial resfriado (retiradas pele, ossos, cartilagens, aponeuroses e vasos), em $3000 \mathrm{~mL}$ de água, com concentração de $1,5 \mathrm{~g}$ de sal de cozinha, cozidos convencionalmente por 30 minutos.

A partir desta preparação, alíquotas de 100 $\mathrm{mL}$ foram separadas em recipientes de aço inoxidável esterilizado para se proceder à infusão de cada um os doze condimentos previamente apresentados, com o caldo em temperatura de ebulição, acrescidos individualmente na quantidade de $10 \mathrm{~g}$, com exceção da pimenta dedo-de-moça a $0,1 \mathrm{~g}$, e da cúrcuma a $0,5 \mathrm{~g}$. Após a adição de cada tempero ao caldo, os recipientes foram tampados por trinta segundos, permitindo a recuperação das gotículas formadas pela evaporação do preparo.

Procedeu-se, então, ao primeiro Teste de Aceitação destas doze espécies, através de análise sensorial compartilhada, utilizando-se escala hedônica estruturada, partindo de "Gostei muitíssimo" (valor arbitrário atribuído equivalente a nove) até "Desgostei muitíssimo" (valor arbitrário atribuído equivalente a um) (Ferreira et al., 2000).

A sequência de apresentação dos condimentos utilizada nas amostras a serem testadas baseou-se na intensidade de aroma e sabor característicos de cada planta condimentar, ordenados daqueles com aroma e sabor menos pronunciados (salsa) até aqueles com aroma e sabor mais pronunciados (pimenta dedo-de-moça), critério esse convencionado pelo grupo.

No segundo Teste de Aceitação, foram utilizadas amostras intencionais com restrição, feitas a partir da aplicação de três diferentes quantidades (pequena, média e grande) dos quatro condimentos classificados. O volume das alíquotas de caldo com frango cozido e o procedimento de infusão mantiveramse idênticos ao anterior. As quantidades médias foram fixadas a partir da quantidade de condimento utilizada nos preparos alimentares da primeira fase de análise sensorial. A partir daí, definiu-se uma quantidade acima e uma quantidade abaixo, estabelecendo-se, respectivamente, quantidades grande e pequena para cada espécie de planta condimentar.

As análises sensoriais foram realizadas no meio do período da manhã (Ferreira et al., 2000), tendo intervalo de uma semana entre o primeiro e o

Rev. Bras. PI. Med., Botucatu, v.13, n.3, p.342-348, 2011. 
segundo testes. Esses intervalos foram estabelecidos objetivando não sobrecarregar o paladar dos provadores, e evitar a perda da memória sensorial dos condimentos adquirida com o treinamento.

As quantidades sensorialmente aceitas no segundo Teste de aceitação sensorial, uma para cada condimento, foram finalmente desafiadas frente a coliforme fecal. Cinco preparos idênticos foram feitos em frascos erlenmeyers de $500 \mathrm{~mL}$, contendo $400 \mathrm{~mL}$ de água destilada, $120 \mathrm{~g}$ de frango e $2 \mathrm{~g}$ de sal de cozinha, sendo autoclavados a $121^{\circ} \mathrm{C}, 1,5 \mathrm{~atm}$, por 20 minutos.

Foram adicionados os condimentos, procedendo-se à infusão por trinta segundos. Os caldos foram denominados Tratamento 1: Controle sem condimento; Tratamento 2, Tratamento 3, Tratamento 4 e Tratamento 5: condimentados. Os Tratamentos foram inoculados com quantidade conhecida de E. coli (ATCC 11229), atingindo concentração final de 10 UFC mL-1, segundo previsão de padrão aceitável pela legislação para pratos à base de carne (Brasil, 2001).

Os inóculos de Escherichia coli (ATCC 11229), provenientes da coleção bacteriológica do Laboratório de Higiene de Alimentos do Instituto de Ciência e Tecnologia de Alimentos da Universidade Federal do Rio Grande do Sul, foram ativados em meio BHI Simples (BHI, OXOID), e incubados a $45^{\circ} \mathrm{C}$, por 24 horas, realizando-se controle biométrico de crescimento segundo Cavalli-Sforza (1974).

Uma vez certificado o crescimento das colônias na contagem em placas, procedeu-se uma nova série de diluições, as quais foram utilizadas nos tratamentos, de acordo com seu volume total final. Assim, foram inoculados, em cada tratamento, 5,22 $\mathrm{mL}$ de Escherichia coli (ATCC 11229) a $10^{-5}$, as quais, uma vez diluídas em $522 \mathrm{~mL}$ de volume final total de cada tratamento, atingiram uma concentração de $10^{-3}$, equivalente a 10 UFC mL-1 , contaminação permitida pela legislação.

Foram retiradas alíquotas de cada um dos tratamentos as duas, quatro, seis, oito, dez e 24 horas pós-inoculação dos coliformes. Essas alíquotas foram semeadas em placas contendo meio seletivo para Escherichia coli, Ágar Chromocult ${ }^{\circledR}$ (Merck), e colocadas sob incubação a $45^{\circ} \mathrm{C}$. Uma vez completadas 24 horas de incubação, foram feitas as contagens em placas, do número de microrganismos em UFCs (Unidades Formadoras de Colônia). Para a análise estatística, foram atribuídos valores arbitrários às contagens efetuadas, conforme Tabela 1, quantificando-se a ausência de crescimento (valor arbitrário atribuído equivalente a seis), crescimento em unidades (valor arbitrário atribuído equivalente a cinco), crescimento em dezenas (valor arbitrário atribuído equivalente a quatro) e crescimento em centenas de UFCs (valor arbitrário atribuído equivalente a três), bem como, crescimento incontável (valor arbitrário atribuído equivalente a dois).

Os dados obtidos foram submetidos à Análise de Variância (ANOVA), seguida de outros procedimentos estatísticos, dentre os quais o Teste de Tukey, permitindo verificar a presença ou ausência de diferença significativa entre as médias obtidas, ao nível de confiança de 95\% (Stone \& Sidel, 1993).

TABELA 1. Representação dos valores ordinais arbitrários atribuídos ao crescimento bacteriano e ausência de crescimento, nas diferentes preparações alimentares condimentadas, expresso em Unidades Formadoras de Colônia por mililitro.

\begin{tabular}{|c|c|c|c|c|}
\hline $\begin{array}{c}\text { Incontável } \\
\left(>\text { que } 300 \text { UFC mL }{ }^{-1}\right)\end{array}$ & 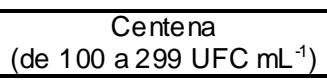 & $\begin{array}{c}\text { Dezena } \\
\text { (de 10 a } 99 \text { UFC } \mathrm{mL}^{-1} \text { ) }\end{array}$ & $\begin{array}{c}\text { Unidade } \\
\text { (de } 1 \text { a } 9 \text { UFC } \mathrm{mL}^{-1} \text { ) }\end{array}$ & $\begin{array}{l}\text { Ausência de } \\
\text { crescimento }\end{array}$ \\
\hline 2 & 3 & 4 & 5 & 6 \\
\hline
\end{tabular}

\section{RESULTADO E DISCUSSÃO}

A análise sensorial das 12 espécies de plantas condimentares, com o objetivo de destacar quatro delas, equivalendo à primeira etapa do experimento, encontra-se expressa pelos valores apresentados na Tabela 2.

A partir dos relatos obtidos após as análises sensoriais, constatou-se que os provadores se apropriaram das características aromáticas e de algumas indicações de uso dos condimentos em preparos alimentares.

As maiores médias obtidas foram para 0 tomilho $(8,11)$, para o alho nirá $(8,44)$, para 0 alho poró $(7,88)$ e para a pimenta dedo-de-moça $(7,77)$. Assim, no modelo alimentar proposto, esses condimentos tiveram melhor aceitação sensorial, classificando-se para a segunda etapa de testes sensoriais.

Observando as médias dos demais condimentos, que não obtiveram notas de aceitação elevadas, é possível afirmar que não foram desagradáveis sensorialmente, mas sim, não foram os mais adequados para serem utilizados nesse tipo de alimento.

Outros dois condimentos obtiveram valores médios também altos no teste de aceitação, a salsa 
TABELA 2. Valores arbitrários (de 9 a 1) atribuídos pelos avaliadores (A) no primeiro Teste de Aceitação para eleição de condimentos em preparo alimentar caldo com frango cozido.

Condimentos

\begin{tabular}{|c|c|c|c|c|c|c|c|c|c|c|c|c|}
\hline 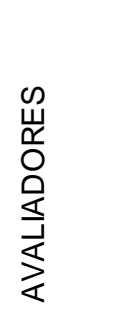 & 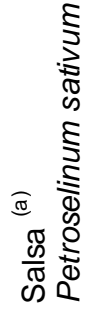 & 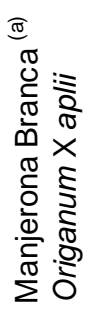 & 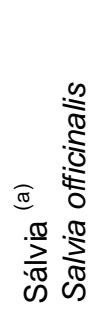 & 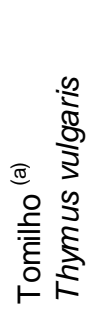 & 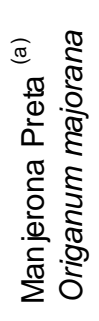 & 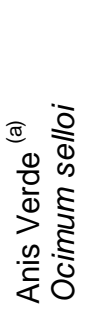 & 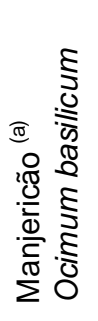 & 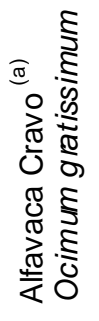 & 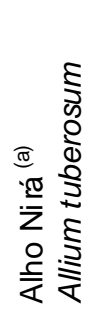 & 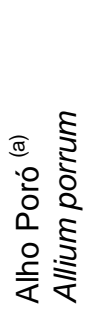 & 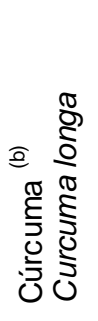 & 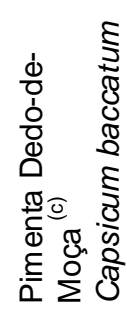 \\
\hline A 1 & 8 & 6 & 3 & 8 & 8 & 4 & 7 & 2 & 9 & 8 & 3 & 8 \\
\hline A 2 & 7 & 6 & 2 & 8 & 7 & 5 & 6 & 4 & 8 & 9 & 2 & 8 \\
\hline A 3 & 8 & 9 & 1 & 9 & 4 & 1 & 6 & 3 & 9 & 5 & 4 & 9 \\
\hline A 4 & 9 & 3 & 2 & 8 & 4 & 6 & 7 & 2 & 9 & 8 & 1 & 9 \\
\hline A 5 & 6 & 8 & 6 & 9 & 8 & 7 & 8 & 5 & 9 & 9 & 4 & 8 \\
\hline A 6 & 7 & 3 & 5 & 6 & 6 & 7 & 8 & 3 & 8 & 7 & 3 & 5 \\
\hline A 7 & 6 & 7 & 3 & 9 & 5 & 2 & 8 & 4 & 9 & 9 & 3 & 8 \\
\hline A 8 & 7 & 5 & 2 & 7 & 7 & 6 & 7 & 4 & 6 & 7 & 2 & 7 \\
\hline A 9 & 8 & 7 & 7 & 9 & 9 & 8 & 9 & 6 & 9 & 9 & 6 & 8 \\
\hline Soma & 66 & 54 & 31 & 73 & 58 & 46 & 66 & 33 & 76 & 71 & 28 & 70 \\
\hline Médias & 7,33 & 6,0 & 3,44 & 8,11 & 6,44 & 5,11 & 7,33 & 3,66 & 8,44 & 7,88 & 3,11 & 7,77 \\
\hline
\end{tabular}

(a) $10 \mathrm{~g}$ de condimento em $100 \mathrm{~mL}$ de caldo, (b) $5 \mathrm{~g}$ de condimento em $100 \mathrm{~mL}$ de caldo, (c) $1 \mathrm{~g}$ de condimento em $100 \mathrm{~mL}$ de caldo

e o manjericão, ambos com nota 7,33. Esse valor permite indicar o uso desses condimentos em preparos à base de frango.

A menor nota atribuída foi para a cúrcuma. Ao término das análises sensoriais, os provadores foram unânimes quanto à proporção aplicada, classificando-a como demasiada, determinando a desqualificação desta planta. Essa constatação reforça a idéia das proporções condimentares a serem utilizadas em preparos alimentares, que devem respeitar suas características e propriedades sensoriais, visando aceitação de consumo.

No segundo Teste de aceitação, as quantidades médias estabelecidas para as espécies condimentares eleitas foram de $1,0 \mathrm{~g}$ para a pimenta dedo-de-moça, de $10 \mathrm{~g}$ para o alho nirá, de $10 \mathrm{~g}$ para o tomilho e para o alho poró. As quantidades pequena e grande para cada condimento podem ser visualizadas na Tabela 3.

A quantidade de condimento a ser aplicada em cada tratamento, eleita a partir das análises, evidencia que a proporção na composição alimentar está relacionada com as características sensoriais. Assim, a pimenta dedo-de-moça, que contém a capsaicina, substância que lhe confere a pungência, foi mais aceita pelos provadores em menor quantidade $\left(0,5 \mathrm{~g} 100 \mathrm{~mL}^{-1}\right)$. Da mesma maneira, o tomilho, com sabor característico forte, em função dos óleos essenciais, foi eleito em menor quantidade $(5 \mathrm{~g} 100$
$\left.\mathrm{mL}^{-1}\right)$. Caso as concentrações definidas para os testes fossem padronizadas a uma mesma quantidade para os diferentes condimentos, correr-se-ia o risco dessas concentrações não serem aplicáveis em alimentos, por intolerância sensorial do consumidor.

As quantidades de condimentos a serem utilizadas em 522 Unidades de Volume de caldo com frango cozido, para os testes bacteriológicos, foram $0,5 \mathrm{~g}$ de pimenta dedo-de-moça (média de 7,2); $15 \mathrm{~g}$ de alho nirá (média de 8,2); $5 \mathrm{~g}$ de tomilho (média de 7,7 ) e $15 \mathrm{~g}$ de alho poró (média de 8,8).

Quando semeadas alíquotas obtidas diretamente dos caldos, sem diluição, segundo o critério estabelecido para contagem do crescimento bacteriano, houve crescimento acima de 300 UFC $\mathrm{mL}^{-1}$ (incontável) em todos os tratamentos, nos diferentes tempos de aferição.

Para que a análise microbiológica fosse conduzida de forma que os resultados obtidos permitissem um julgamento correto dos produtos analisados, foi feita diluição das alíquotas obtidas de cada tratamento. Desta forma, pesquisando o número de Unidades Formadoras de Colônia em meio seletivo para coliformes fecais, a partir de diluições de $10^{-1}$, a atividade antibacteriana de cada condimento testado ficou claramente estabelecida.

$\mathrm{Na}$ Tabela 4, podem ser visualizados os valores ordinais arbitrários atribuídos ao crescimento bacteriano nos Tratamentos de 1 a 5, expresso em 
TABELA 3. Valores médios obtidos no segundo Teste de Aceitação para diferentes quantidades de Pimenta Dedode-Moça (Capsicum baccatum), Alho Nirá (Allium tuberosum), Tomilho (Thymus vulgaris) e Alho Poró (Allium porrum) acrescidas em preparo alimentar caldo com frango cozido.

\begin{tabular}{|c|c|c|c|}
\hline \multirow[b]{2}{*}{ Condimentos } & \multicolumn{3}{|c|}{ Quantidades (g) em $100 \mathrm{~mL}$ de caldo com frango cozido } \\
\hline & Pequena & Média & Grande \\
\hline & $0,5{\mathrm{~g} 100 \mathrm{~mL}^{-1}}^{2}$ & $1,0{\mathrm{~g} \mathrm{~g} 100 \mathrm{~mL}^{-1}}^{-1}$ & $2,0{\mathrm{~g} 100 \mathrm{~mL}^{-1}}^{-1}$ \\
\hline Dedo-de-Moça & 7,2 & 5,8 & 2,0 \\
\hline & $5{\mathrm{~g} 100 \mathrm{~mL}^{-1}}^{-1}$ & $10{\mathrm{~g} 100 \mathrm{~mL}^{-1}}^{-1}$ & $15{\mathrm{~g} 100 \mathrm{~mL}^{-1}}^{-1}$ \\
\hline Alho Nirá & 6,1 & $\mathbf{7 , 7}$ & 8,2 \\
\hline & $5{\mathrm{~g} 100 \mathrm{~mL}^{-1}}^{-1}$ & $10{\mathrm{~g} 100 \mathrm{~mL}^{-1}}^{-1}$ & $15{\mathrm{~g} 100 \mathrm{~mL}^{-1}}^{-1}$ \\
\hline Tomilho & 7,7 & 5,6 & 4,0 \\
\hline & $5 \mathrm{~g} 100 \mathrm{~mL}^{-1}$ & $10{\mathrm{~g} 100 \mathrm{~mL}^{-1}}^{-1}$ & $15{\mathrm{~g} 100 \mathrm{~mL}^{-1}}^{-1}$ \\
\hline Alho Poró & 8,3 & 8,8 & 8,8 \\
\hline
\end{tabular}

TABELA 4. Valores ordinais arbitrários atribuídos ao crescimento de coliformes fecais nos Tratamentos de 1 a 5 (T1 a T5), segundo o número de Unidades Formadoras de Colônias encontradas em $10^{-1}$ ( $\left.1 \mathrm{UFC} \mathrm{mL}^{-1}\right)$, em diferentes tempos (h) de aferição.

\begin{tabular}{ccccccc}
\hline & \multicolumn{3}{c}{ Tratamentos } & & $\begin{array}{c}\text { Médias dos } \\
\text { tempos }\end{array}$ \\
\hline Tempo (h) & $\begin{array}{c}\text { T1 } \\
\text { Controle }\end{array}$ & $\begin{array}{c}\text { T2 } \\
\text { Dedo-de-Moça }\end{array}$ & $\begin{array}{c}\text { T3 } \\
\text { Nirá }\end{array}$ & $\begin{array}{c}\text { T4 } \\
\text { Poró }\end{array}$ & $\begin{array}{c}\text { T5 } \\
\text { Tomilho }\end{array}$ \\
\hline 2 & 2 & 6 & 4 & 4 & 4 & $4,5^{\mathrm{a}}$ \\
4 & 2 & 3 & 4 & 3 & 3 & $3,25^{\mathrm{b}}$ \\
6 & 2 & 3 & 3 & 2 & 2 & $2,5^{\mathrm{bc}}$ \\
8 & 2 & 2 & 3 & 2 & 2 & $2,25^{\mathrm{c}}$ \\
10 & 2 & 2 & 2 & 2 & 2 & $2^{\mathrm{c}}$ \\
24 & 2 & 2 & 2 & 2 & 2 & $2^{\mathrm{c}}$ \\
\hline Médias dos & $2^{\mathrm{A}}$ & $3^{\mathrm{A}}$ & $3^{\mathrm{A}}$ & $2,5^{\mathrm{A}}$ & $2,5^{\mathrm{A}}$ & \\
tratamentos & & & & & & \\
\hline
\end{tabular}

Médias com letras maiúsculas iguais na linha indicam que não há diferença significativa a 5\% de probabilidade pelo Teste de Tukey. Médias com pelo menos uma mesma letra minúscula na coluna não diferem significativamente entre si, e com letras minúsculas diferentes na mesma coluna, indicam diferença significativa a $5 \%$ de probabilidade pelo Teste de Tukey.

Unidades Formadoras de Colônia por mililitro (UFC $\left.\mathrm{mL}^{-1}\right)$, segundo os tempos de incubação expressos em horas, encontradas em $10^{-1}$ (1 UFC mL-1).

O crescimento de coliformes fecais no Tratamento Controle foi acima de 300 UFC $\mathrm{mL}^{-1}$ (valor arbitrário 2) em todos os tempos de aferição. Comparados ao controle, todos os tratamentos condimentados apresentaram, individualmente, atividade antibacteriana significativa, mesmo que sem significância quando comparados entre si (médias dos tratamentos sem diferença significativa).

No Tratamento 2, caldo com a pimenta dedode-moça, não houve crescimento bacteriano (valor arbitrário atribuído 6) nas primeiras duas horas após a inoculação. Após a quarta hora, essa atividade antibacteriana promovida pela pimenta foi menor, sendo que o crescimento foi centesimal (valor 3), mantendo-se assim após seis horas da inoculação. Das oito horas em diante, o crescimento bacteriano atingiu números incontáveis (valor 2).

Nos tratamentos com alho nirá, alho poró e tomilho, houve crescimento decimal de Unidades Formadoras de Colônia (valor 4), nas primeiras duas horas após inoculação.

Às quatro horas de aferição, o Tratamento 3 (alho nirá) se manteve nessa contagem, porém os Tratamentos 4 (alho poró) e 5 (tomilho) apresentaram maior crescimento (valor 3 ). 0 Tratamento 3 não 
apresentou aumento do número de UFCs da sexta para a oitava hora pós-inoculação, fato que ocorreu para todos os demais tratamentos.

Dessa forma, em relação ao tempo de início da atividade antibacteriana, destacou-se a pimenta dedo-de-moça, enquanto que, em relação ao prolongamento dessa ação no tempo, destacou-se o alho nirá.

Diante do exposto conclui-se que:

Diferentes condimentos vegetais foram capazes de fornecer qualificação sensorial a caldo com frango cozido, respeitadas proporções, concentrações e combinações previamente sinalizadas.

A capacitação de um grupo de provadores quanto a plantas condimentares, sua real identificação, apresentação, aroma e sabor, foi imprescindível para a detecção sensorial subsequente dessas características, quando de sua aplicação na condimentação desse alimento.

O treinamento dos provadores de alimentos mostrou-se uma ferramenta e uma experiência efetiva no sentido de agregação de conhecimentos, habilidades, motivações e significados sobre as plantas condimentares, especialmente aquelas desconhecidas pelos participantes, oportunizando a sua apropriação no cotidiano da alimentação e nutrição dos protagonistas.

Em relação ao desafio antibacteriano, todos os tratamentos condimentados apresentaram, individualmente, atividade anti- Escherichia coli. Em relação à intensidade do tempo de início desta atividade destacou-se a pimenta dedo-de-moça, enquanto que, em relação ao prolongamento dessa atividade no tempo, destacou-se o alho nirá.

Pimenta dedo-de-moça, alho nirá, alho poró e tomilho podem ser usados como antibacterianos naturais, em condições domésticas de manuseio de alimentos, reduzindo o risco da contaminação de alimento de origem animal tipo caldo de frango e conferindo qualificação sensorial ao mesmo.

\section{REFERÊNCIA}

BACKES, A.; NARDINO, M. Nomes populares e científicos de plantas do Rio Grande do Sul. 2 ed. São Leopoldo: Editora Unisinos, 2001. 202p.

BRASIL. Ministério da Saúde. Conselho Nacional de Saúde. Resolução CNS no 196, de 10 de outubro de 1996. Diretrizes e normas regulamentadoras de pesquisas envolvendo seres humanos. Comissão Nacional de Ética em Pesquisa. Disponível em: <http:// conselho.saude.gov.br/comissao/conep/resolucao. html>. Acesso em: 20 abr. 2009.

BRASIL. Resolução RDC o 12, de 02 de janeiro de 2001. Aprova Regulamento Técnico sobre Padrões Microbiológicos para Alimentos. Diário Oficial da União, Brasília, DF. 10 jan. 2001. Disponível em: <http://www. anvisa.gov.br/legisl/resol/12_01rdc.htm>. Acesso em: 20 abr. 2009.

BREMNESS, L. Plantas aromáticas: guia prático. Londres: Dorling Kingerley, 1993. 240p.

CAVALLI-SFORZA, L. Biometrie: grundzüge biologischmedizinische Statistik. Stuttgart: Gustav Fisher, 1974. p.201-4.

CARVALHO, H.H.C. et al. Atividade antibacteriana em plantas com indicativo etnográfico condimentar em Porto Alegre, RS/Brasil. Revista Brasileira de Plantas Medicinais, v.7, n.3, p.25-32, 2005.

FERREIRA, V.L.P. et al. Análise sensorial: testes discriminativos e afetivos. Campinas: SBCTA, 2000. 127p. (Manual Série Qualidade).

FURLAN, M.R. Dossiê técnico cultivo de plantas condimentares herbáceas. Belo Horizonte: Fundação Centro Tecnológico de Minas Gerais/CETEC, 2007. 29p. GERMANO, P.M.L.; GERMANO, M.I.S. Higiene e vigilância sanitária de alimentos. São Paulo: Livraria Varela, 2003. p.62-3.

LORENZI, H.; MATOS, F.J.A. Plantas medicinais no Brasil: nativas e exóticas. 3.ed. Nova Odessa: Instituto Plantarum, 2002. 544p.

MARANCA, G. Plantas aromáticas na alimentação. São Paulo: Nobel, 1985. p.104-7.

MARODIN, S. Identificação botânica das espécies condimentares: projeto produtos lácteos condimentados, atividade antibacteriana de condimentos vegetais sobre contaminantes e inóculos padronizados (CNPq $\mathrm{n}$ 응 523193). Porto Alegre, RS, 2004. 8p. (Relatório Técnico). MING, L.C. Coleta de plantas medicinais. In: DI STASI, L.C.(Org.). Plantas medicinais: arte e ciência. Um guia de estudo interdisciplinar. São Paulo: Editora da Universidade Estadual Paulista, 1996. cap. 6, p.69-86. NOTÍCIAS DE MERCADO. Frango e suíno ganham fatia da carne bovina. Disponível em: <http://www. noticiasagricolas.com.br/noticias. php?id=43224>. Acesso em: 30 jun. 2009.

RENNARD, B.O. et al. Chicken soup inhibits neutrophil chemotaxis in vitro. Chest Journal, American College of Chest Physicians, v.118, n.4, p.1150-7, 2000.

SAFRAS \& MERCADO. Carnes: consumo per capita de frango no Brasil chegou a 38,7 quilos. Disponível em: <http://ultimosegundo.ig.com.br/economia/safra/2009/ 01/20/.html>. Acesso em: 30 jun. 2009.

STONE, H.; SIDEL, J.L. Sensory evaluation statistics practices. New York: Academic Press, 1993. 338p. 